\section{p-ISSN 2476-9886 \\ e-ISSN 2477-0302 \\ J.Edu}

Volume 4 Nomor 1, April 2018, HIm 1-6

\section{Jurnal EDUCATIO}

Jurnal Pendidikan Indonesia

DOI: https://doi.org/10.29210/120182131

Akses Online :

http://jurnal.iicet.org

Dipublikasikan oleh :

Indonesian Institute for Counseling, Education and Therapy (IICET)

Info Artikel:

Diterima: 03/03/2018

Direvisi: $12 / 03 / 2018$

Dipublikasikan: 15/04/2018

\title{
PENERAPAN INVENTORY TES GAYA BELAJAR REMAJA DENGAN APLIKASI GOOGLE FORM, MEDIA SOSIAL SERTA PENGEMBANGAN PROGRAM LAYANAN BIMBINGAN DAN KONSELING TERKAIT
}

\begin{abstract}
Yuyun Mashurwati ${ }^{1}$
${ }^{1}$ MTs Negeri 17 Jakarta

Abstract

Student learning outcomes are low and not optimal is a common problem that occurs in adolescents in almost all schools in Indonesia. One reason, teachers are less than optimal in accommodating student learning styles. This text tries to offer an alternative that teachers can do, especially BK teachers / counselors, to introduce learning styles using very easy-to-create applications using the google form application and utilizing social media for socialization. This paper only provides a brief description, so for the future need further research and follow-up.
\end{abstract}

Keyword: learn style, guidance and counseling, google form, social media

(c) (1) This is an open access article distributed under the Creative Commons Attribution License, which permits unrestricted use, distribution, and reproduction in any medium, provided the original work is properly cited. C2017 by author and Indonesian Counselor Association (IKI).

\section{PENDAHULUAN}

Hasil belajar yang rendah merupakan persoalan yang umum pada setiap sekolah di Indonesia. Banyak survey yang menunjukkan hasil kualitas pendidikan Indonesia masih tergolong rendah (Firman \& Tola, 2008). Berdasarkan gambaran dari The Trends in International Mathematics and Science Study (TIMSS) tahun 2007 dan The Programme for International Student Assessment (PISA) tahun 2006 menunjukkan bahwa kemampuan matematika anak indonesia berada dibawah skor rata-rata internasional, dan juga pada Progress in International Reading Literacy Study (PIRLS) tahun 2006 menunjukkan kemampuan membaca anak di indonesia berada diurutan lima terbawah internasional dari 45 negara maju (Tjalla, 2010). Jika dilihat dari jumlah jam pelajaran, Indonesia memiliki jumlah jam pelajaran lebih banyak dari Negara maju lainnya yakni sebanyak 1.095 jam pelajaran per tahun. Jika dibandingkan dengan Korea Selatan hanya 903 jam pelajaran per tahun dan Jepang yang memberlakukan 712 jam pelajaran per tahun. Seharusnya Indonesia lebih berhak berada pada tingkat atas dunia karena jumlah jam pelajarannya jauh lebih banyak, namun justru kedua Negara tersebut yang berada di peringkat atas dunia (Krisiandi, 2016).Hal ini tentu menjadi penting untuk dicermati. 
Berbagai faktor yang menjadi penyebab rendahnya kualitas pendidikan, salah satu penyebabnya adalah kualitas guru dan metode yang digunakannya tidak tepat (Inayah, 2013). Guru cendrung menggunakan metode yang sama untuk setiap siswa, hal itu tentu tidak bisa mengakomodir untuk setiap siswa yang memiliki berbagai keunikan dan tipe gaya belajar (Ramlah, Firmansyah, \& Zubair, 2015), kesulitan memilih metode juga dialami oleh guru bimbingan dan konseling/konseling di sekolah (Sandra \& Ifdil, 2015). Seyogyanya pendidikan harusnya mengedepankan proses mendidik dan tidak hanya hanya bertugas mengajar saja (Dahlan, Refnadi, \& Zufriani, 2017). Upaya ini harusnya dapat dilakukan dengan memperhatikan gaya belajara siswa.

Gaya belajar merupakan kombinasi bagaimana anak menyerap dan mengolah informasi, hal ini akan berbeda pada setiap pribadi anak (Prashnig, 2007). Meskipun terdapat perbedaan gaya belajar siswa, tujuan yang hendak dicapai adalah sama yakni agar anak memahami dan mengerti yang diajarkan oleh gurunya (Pendidikan, 2007), sehingga guru harus memiliki metode yang tepat untuk menganalisa setiap siswanya dan memberikan metode yang tepat untuk mengakomodir setiap keunikan gaya belajar siswa.

Tidak banyak siswa remaja yang mengetahui tipe gaya belajar, bahkan guru juga tidak mengetahui hal tersebut (Arifin, 2014). Sosialisasi kepada guru dan para siswa tentang gaya belajar sangat penting dilaksanakan guna meningkatkan kualitas pembelajaran, pemanfaatan teknologi dinilai akan menjadi langkah yang tepat untuk dilaksanakan.

Teknologi saat ini semakin maju dan berkembang sehingga melahirkan masyarakat digital (Ngafifi, 2014). Survey yang dilakukan pada $78 \mathrm{kota} / \mathrm{kabupaten}$ dan 33 provinsi pada akhir 2013 menunjukkan bahwa pengguna internet di Indonesia mencapai 71,19 juta, dan angka tersebut terus akan bertambah, diantara penyebabnya karena smartphone, komputer, laptop, tablet yang semakin mudah didapat dan semakin murah (Manumpil, Ismanto, \& Onibala, 2015). Hampir setiap orang sudah memiliki gadget yang bisa digunakan untuk mengakses internet, tidak terkecuali para remaja. Keakraban masyarakat dengan teknologi menjadi peluang yang bagus untuk dimanfaat dalam proses pendidikan, ini akan menjadi menarik untuk dimanfaatkan dalam rangka menganalilis tipe gaya belajar siswa dengan memanfaatkan google form.

\section{PEMBAHASAN}

Google form bisa menjadi alternatif bagi guru terutama guru bimbingan dan konseling/konselor untuk mengidentifikasi gaya belajar siswa, yang lebih lanjut digunakan untuk keperluan pelaksanaan pembelajaran/pelayanan dengan memanfaatkan media sosial sebagai alternatif dalam sosialiasi. Nashkah ini lebih lanjut akan memaparkan tentang gaya belajar, google form, media sosial, dan bagaimana ketiga aspek itu terintegrasi dalam pelayanan bimbingan dan konseling.

\section{Gaya Belajar}

Setiap anak memiliki karakteristik dan tipe gaya belajar sendiri (Priyatna, 2013; Sari, 2014). terdapat tiga gaya belajar pada setiap siswa. Pertama visual, anak visual cenderung lebih mudah belajar dari yang dilihat dan diamati. Kedua audiotorial, anak audiotorial lebih mudah belajar dari apa yang mereka dengar, Ketiga kinestetik, anak kinestetik lebih mudah belajar melalui gerakan dan sentuhan (Fajar Dwi, 2012). Bagi anak visual membaca akan memudahkan mereka untuk belajar, untuk anak audiotorial lebih mudah belajar jika informasi disampaikan oleh orang lain tidak melalui membaca, sedangkan anak kinestetik lebih mudah belajar jika mereka mempraktekkan teori tersebut secara langsung. 


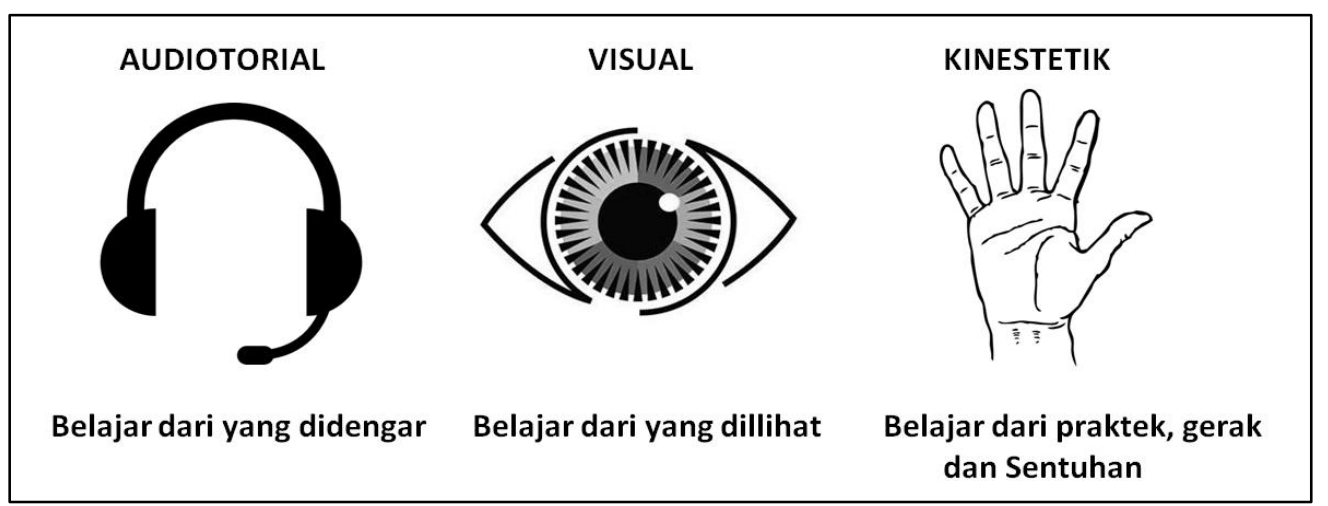

Grafik 1. Gaya belajar Siswa

Penelitian oleh Bire menunjukkan hubungan yang signifikan antara gaya belajar dan prestasi belajar (Bire \& Bire, 2014). Jika anak mengetahui gaya belajarnya, lebih mudah bagi mereka menyesuaikan diri dengan pelajaran. Sebagai contoh, bagi anak audiotorial bisa belajar bersama dengan anak visual, anak visual membacakan pelajaran sedangkan anak audio mendengarkan, hal ini akan membentuk kolaborasi yang baik.

Markova dkk didalam bukunya "How your child is smart" tahun 1996 menekankan bahwa setiap orang menggunakan ketiga metode gaya belajar dalam urutan yang berbeda, meskipun demikian setiap orang memiliki gaya yang dominan (Markova \& Powell, 1996).

Bagi guru, memahami karakteristik gaya belajar siswa akan lebih mengakomodir perbedaan tipe gaya belajar siswa. Hal ini bertujuan agar siswa lebih memusatkan perhatian mereka kepada apa yang dilakukan oleh guru (Halim, 2012). Pemusatan perhatian sangat penting dalam proses pembelajaran, baik itu ketika guru menjelaskan pelajaran, meminta anak membacakan pelajaran, atau mempraktekkan secara langsung materi pelajaran.

Tabel 1. Kriteria Kebiasaan siswa berdasarkan kategori Audiotorial, Visual, Kinestetik

\begin{tabular}{|c|c|c|c|}
\hline Kategori & Audiotorial & Visual & Kinestetik \\
\hline Belajar & $\begin{array}{l}\text { Sambil mendengarkan } \\
\text { musik }\end{array}$ & $\begin{array}{l}\text { Membaca dengan keadaan } \\
\text { yang tenang }\end{array}$ & $\begin{array}{l}\text { Suka menggerakkan } \\
\text { anggota tubuh }\end{array}$ \\
\hline Menerima penjelasan & Kata-kata verbal & Tulisan/gambar/peta/sketsa & Praktik langsung \\
\hline Penyampaian Emosi & $\begin{array}{l}\text { Secara verbal melalui } \\
\text { perubahan nada dan vocal }\end{array}$ & Melalui ekspresi muka & $\begin{array}{l}\text { Melalui bahasa tubuh } \\
\text { gerak/otot }\end{array}$ \\
\hline Berbicara & $\begin{array}{l}\text { Berbicara dengan } \\
\text { kecepatan sedang tetapi } \\
\text { tergolong suka bicara }\end{array}$ & $\begin{array}{l}\text { Cenderung berbicara } \\
\text { cepat, tetapi tergolong } \\
\text { pendiam }\end{array}$ & Berbicara agak lambat \\
\hline Hobi & $\begin{array}{l}\text { Suka mendengar musik, } \\
\text { radio, debat }\end{array}$ & membaca, menonton TV & Menyukai kegiatan aktif \\
\hline Berkomunikasi & $\begin{array}{l}\text { Dialog dan berbicara } \\
\text { terbuka }\end{array}$ & $\begin{array}{l}\text { Melalui tatapan mata dan } \\
\text { ekspresi wajah }\end{array}$ & $\begin{array}{l}\text { Lewat sentuhan, dan } \\
\text { keakraban }\end{array}$ \\
\hline
\end{tabular}

Sumber: (Dunn, 1990; Farida, 2013; Gholami \& Bagheri, 2013; NAFISAH, 2017) 


\section{Google Form}

Google form merupakan layanan yang bisa digunakan untuk membuat quiz, form dan survey online, fitur ini dapat dibagikan ke orang lain atau siapa saja yang dihendaki pengguna. Berbagai keuntungan dari google form 1) tampilan form menarik 2) responden bisa memberikan tanggapan segera dan dimana saja 3) hasil langsung dianalisis dan tersusun otomatis, dan berbagai keuntungan lainnya (Batubara, 2016). Hal ini bisa sangat membantu guru dalam membuat kuisoner untuk menganalisis tipe belajar siswa, disamping tampilan yang menarik untuk para remaja, juga akan lebih efektif dan efisien untuk digunakan.

\section{Media sosial}

Media sosial merupakan media online yang bisa digunakan untuk memberikan dan mendapatkan informasi, serta menjadi alat komunikasi (Utami \& Triyono, 2013). Media ini digunakan untuk sosialisasi dan komunikasi mengenai penggunaan tes gaya belajar, baik itu memperkenalkan google form, untuk berdiskusi, serta tindak lanjut hasil tes gaya belajar. Banyak media sosial yang bisa digunakan seperti whatsapp, facebook, blackberry messenger, line, dan lainnya.

\section{Pengadministrasian Inventory Gaya Belajar dalam Bimbingan dan Konseling}

Guru bimbingan dan konseling/konselor di sekolah membantu para siswa dalam perkembangan pribadi, sosial, belajar, dan karir (BK \& HAFID, 2007; Ifdil, 2010). Dalam melaksanakan pelayanan bimbingan dan konseling di sekolah terdapat berbagai jenis layanan dan kegiatan pendukung, diantara kegiatan pendukungnya adalah aplikasi intrumentasi (Kamaluddin, 2011; Sudrajat, 2008), terdapat banyak aplikasi intrumentasi yang menunjang kinerja pelayanan bimbingan dan konseling di sekolah, diantaranya alat ungkap masalah (AUM), daftar cek masalah (DCM), inventori tugas perkembangan (ITP), sosiometri, dan lainnya (Khoiriah, 2010; Nurrahmi, 2015; Wahyuni, 2016).

Seiring perjalanan waktu, e-counseling telah berkembang dalam dunia konseling, yakni memanfaatkan elektronik dalam konseling, termasuk juga didalamnya pemanfaatan teknologi informasi dan komunikasi dalam penyenggaraan BK (Ardi, Yendi, \& Ifdil, 2013; Ifdil \& Ardi, 2013). Hal ini dilakukan untuk menunjang pelaksanaan pelayanan BK di sekolah dan membantu perkembangan siswa dalam bidang pribadi, sosial, pendidikan, dan karir. Pengaplikasian inventory gaya belajar bisa bermanfaat bagi para guru mata pelajaran dan para siswa untuk mengenal gaya belajar dominan yang melekat pada tiap individu siswa.

Pada tahap awal inventory gaya belajar didesain dan dibuat melalui aplikasi google form dengan memasukkan berbagai pertanyaan dan jawaban terkait dengan gaya belajar, ketika sudah siap digunakan guru, guru $\mathrm{BK} /$ Konselor melaksanakan pengadministrasian dengan memanfaatkan media sosial sebagai alat sosialisasi.

\section{SIMPULAN DAN SARAN}

Setiap anak memiliki karakteristik dan tipe gaya belajar sendiri, baik itu visual, audiotorial, dan kinestetik. Pengetahuan mengenai gaya belajar penting dimiliki oleh setiap guru dan setiap siswa untuk meningkatkan metode pembelajaran dan prestasi belajar. Penerapan inventory tes gaya belajar dengan menggunakan google form bisa menjadi alternatif bagi guru mata pelajaran, guru BK/Konselor dalam upaya membantu peningkatan kualitas pembelajaran, terutama bagi para guru di MTs Negeri 17 Jakarta . kedepan perlu penelitian lebih lanjut dan tindak lanjut dari data hasil aplikasi ini yang berguna untuk mengoptimalkan pelayanan guru dalam hal mengakomodir gaya belajar serta meningkatkan pelayanan bimbingan dan konseling untuk keperluan optimalisasi siswa melalui optimalisasi implikasi gaya belajar.

\section{DAFTAR RUJUKAN}

Ardi, Z., Yendi, F. M., \& Ifdil, I. (2013). Konseling Online: Sebuah Pendekatan Teknologi Dalam Pelayanan Konseling. Jurnal Konseling dan Pendidikan, 1(1), 1-5.

Arifin, Z. (2014). MENJADI GURU PROFESIONAL (ISU DAN TANTANGAN MASA DEPAN). edutech, 13(1), 132-155.

Batubara, H. H. (2016). Penggunaan Google Form Sebagai Alat Penilaian Kinerja Dosen di Prodi PGMI Uniska Muhammad Arsyad Al Banjari. Al-Bidayah: Jurnal Pendidikan Dasar Islam, 8(1), 39-50. 
Bire, A. L., \& Bire, J. (2014). Pengaruh gaya belajar visual, auditorial, dan kinestetik terhadap prestasi belajar siswa. Jurnal Kependidikan: Penelitian Inovasi Pembelajaran, 44(2).

BK, B. S. U. G., \& HAFID, D. H. (2007). Rambu-Rambu Penyelenggaraan Bimbingan dan Konseling dalam Jalur Pendidikan Formal.

Dahlan, D., Refnadi, R., \& Zufriani, Z. (2017). Pengintegrasian Motif Ibadah Pendidik Sebagai Upaya Optimalisasi Pencapaian Tujuan Pendidikan. Jurnal Konseling dan Pendidikan, 5(3), 115-122.

Dunn, R. (1990). Understanding the Dunn and Dunn learning styles model and the need for individual diagnosis and prescription. Reading, Writing, and Learning Disabilities, 6(3), 223-247.

Fajar Dwi, P. (2012). Pengaruh gaya belajar terhadap prestasi belajar Mata diklat listrik otomotif siswa kelas xi teknik Perbaikan bodi otomotif smkn 2 depok sleman. UNIVERSITAS NEGERI YOGYAKARTA.

Farida, E. (2013). Perbedaan pengaruh antara Gaya Belajar Visual, Auditori, dan Kinestetik terhadap Prestasi Belajar pada Mata Pelajaran PKn Siswa Kelas XA dan XB SMK PGRI 2 Salatiga Semester II Tahun Pelajaran 2011/2012. Program Studi Pendidikan Pancasila dan Kewarganegaraan FKIP-UKSW.

Firman, H., \& Tola, B. (2008). The future of schooling in Indonesia. Journal of International Cooperation in Education, 11(1), 71-84.

Gholami, S., \& Bagheri, M. S. (2013). Relationship between VAK Learning Styles and Problem Solving Styles regarding Gender and Students' Fields of Study. Journal of Language Teaching \& Research, 4(4).

Halim, A. (2012). Pengaruh strategi pembelajaran dan gaya belajar terhadap hasil belajar fisika siswa SMP N 2 Secanggang Kabupaten Langkat. Jurnal Tabularasa, 9(2), 141-158.

Ifdil, I. (2010). Pendidikan Karakter dalam Bimbingan dan Konseling. Pedagogi: Jurnal Ilmu Pendidikan, 10(2), $55-61$.

Ifdil, I., \& Ardi, Z. (2013). Konseling Online Sebagai Salah Satu Bentuk Pelayanan E-konseling. Jurnal Konseling dan Pendidikan, 1(1), 15-22.

Inayah, R. (2013). Pengaruh kompetensi guru, motivasi belajar siswa, dan fasilitas belajar terhadap prestasi belajar mata pelajaran ekonomi pada siswa kelas XI IPS SMA Negeri 1 Lasem Jawa Tengah Tahun Pelajaran 2011/2012. Jurnal pendidikan insan mandiri, 2(1).

Kamaluddin, H. (2011). Bimbingan dan konseling sekolah. Jurnal Pendidikan dan Kebudayaan, 17(4), 447-454.

Khoiriah, A. (2010). PEMANFAATAN INVENTORI TUGAS PERKEMBANGAN (ITP) DALAM PEMBUATAN PROGRAM BIMBINGAN DAN KONSELING DI SMPN 21 PEKANBARU. Universitas Islam Negeri Sultan Syarif Kasim Riau.

Krisiandi. (2016, 15 Desember 2016). Daya Imajinasi Siswa Lemah. Harian Kompas, 11.

Manumpil, B., Ismanto, A. Y., \& Onibala, F. (2015). Hubungan penggunaan gadget dengan tingkat prestasi siswa di SMA Negeri 9 Manado. Jurnal Keperawatan, 3(2).

Markova, D., \& Powell, A. R. (1996). How your child is smart: A life-changing approach to learning: Conari Press.

NAFISAH, N. R. (2017). PENGARUH GAYA BELAJAR TERHADAP PRESTASI BELAJAR MATA PELAJARAN PENDIDIKAN AGAMA ISLAM SISWA KELAS XI DI SMA NEGERI 1 TULUNGAGUNG TAHUN AJARAN 2016-2017.

Ngafifi, M. (2014). Kemajuan teknologi dan pola hidup manusia dalam perspektif sosial budaya. Jurnal Pembangunan Pendidikan: Fondasi dan Aplikasi, 2(1).

Nurrahmi, H. (2015). Kompetensi profesional guru bimbingan dan konseling. Al-Hikmah, 9(1).

Pendidikan, B. S. N. (2007). Standar Proses untuk Satuan Pendidikan Dasar dan Menengah. Badan Standar Nasional Pendidikan.

Prashnig, B. (2007). The Power of Learning Styles: Mendongkrak Anak Melejitkan Prestasi dengan Mengenali Gaya Belajarnya: Kaifa.

Priyatna, A. (2013). Pahami Gaya Belajar Anak! : Elex Media Komputindo.

Ramlah, R., Firmansyah, D., \& Zubair, H. (2015). Pengaruh Gaya Belajar dan Keaktifan Siswa Terhadap Prestasi Belajar Matematika (Survey Pada SMP Negeri di Kecamatan Klari Kabupaten Karawang). Majalah Ilmiah SOLUSI, 1(03).

Sandra, R., \& Ifdil, I. (2015). Konsep Stres Kerja Guru Bimbingan dan Konseling. Jurnal EDUCATIO: Jurnal Pendidikan Indonesia, 1(1), 80-85.

Sari, A. K. (2014). Analisis Karakteristik Gaya Belajar VAK (Visual, Auditorial, Kinestetik) Mahasiswa Pendidikan Informatika Angkatan 2014. Edutic-Scientific Journal of Informatics Education, 1(1). 
Sudrajat, A. (2008). Bimbingan dan Konseling di Sekolah. Tersedia di: http://akhmadsudrajat. wordpress. com/2008/02/10/bk-dan-mpmbs/.(16 Januari 2009).

Tjalla, A. (2010). Potret mutu pendidikan indonesia ditinjau dari hasil-hasil studi internasional.

Utami, A. D., \& Triyono, R. A. (2013). Pemanfaatan Blackberry Sebagai Sarana Komunikasi Dan Penjualan Batik Online Dengan Sistem Dropship Di Batik Solo 85. Speed-Sentra Penelitian Engineering dan Edukasi, 3(3).

Wahyuni, S. (2016). ASSESSMENT DALAM BIMBINGAN DAN KONSELING. Hikmah, 10(2). 